\title{
Atomic-scale insights into electro-steric substitutional chemistry of cerium oxide
}

Zhang, Haiwu; Castelli, Ivano Eligio; Santucci, Simone; Sanna, Simone; Pryds, Nini; Esposito, Vincenzo

Published in:

Physical Chemistry Chemical Physics

Link to article, DOI:

10.1039/DOCP03298K

Publication date:

2020

Document Version

Peer reviewed version

Link back to DTU Orbit

Citation (APA):

Zhang, H., Castelli, I. E., Santucci, S., Sanna, S., Pryds, N., \& Esposito, V. (2020). Atomic-scale insights into electro-steric substitutional chemistry of cerium oxide. Physical Chemistry Chemical Physics, 22(38), 2190021908. https://doi.org/10.1039/D0CP03298K

\section{General rights}

Copyright and moral rights for the publications made accessible in the public portal are retained by the authors and/or other copyright owners and it is a condition of accessing publications that users recognise and abide by the legal requirements associated with these rights.

- Users may download and print one copy of any publication from the public portal for the purpose of private study or research.

- You may not further distribute the material or use it for any profit-making activity or commercial gain

- You may freely distribute the URL identifying the publication in the public portal 

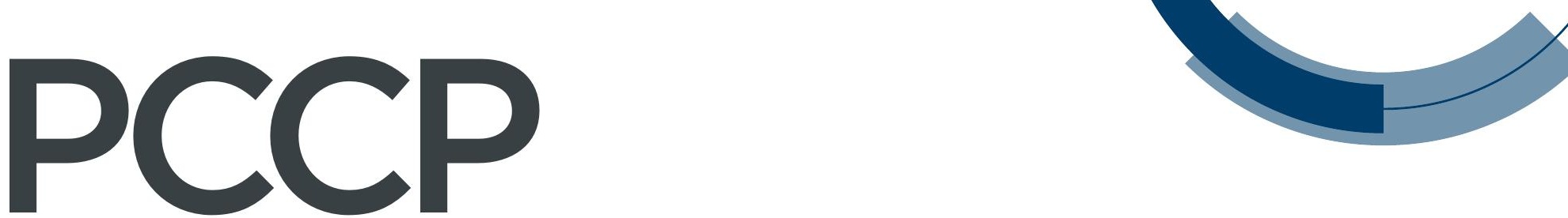

Physical Chemistry Chemical Physics

\section{Accepted Manuscript}

This article can be cited before page numbers have been issued, to do this please use: H. Zhang, I. E.

Castelli, S. Santucci, S. Sanna, N. Pryds and V. Esposito, Phys. Chem. Chem. Phys., 2020, DOI:

10.1039/DOCP03298K.
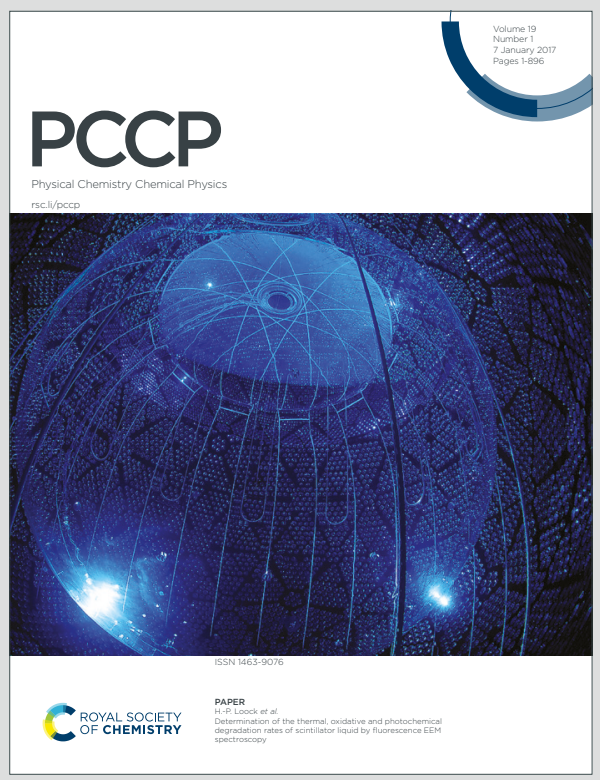

This is an Accepted Manuscript, which has been through the Royal Society of Chemistry peer review process and has been accepted for publication.

Accepted Manuscripts are published online shortly after acceptance, before technical editing, formatting and proof reading. Using this free service, authors can make their results available to the community, in citable form, before we publish the edited article. We will replace this Accepted Manuscript with the edited and formatted Advance Article as soon as it is available.

You can find more information about Accepted Manuscripts in the Information for Authors.

Please note that technical editing may introduce minor changes to the text and/or graphics, which may alter content. The journal's standard Terms \& Conditions and the Ethical guidelines still apply. In no event shall the Royal Society of Chemistry be held responsible for any errors or omissions in this Accepted Manuscript or any consequences arising from the use of any information it contains. 


\section{Atomic-scale insights into electro-steric substitutional chemistry of cerium oxide}

Received 00th January 20xx, Accepted 00th January 20xx

DOI: $10.1039 / \times 0 \times x 00000 x$

www.rsc.org/

\author{
Haiwu Zhang, Ivano E. Castelli*, Simone Santucci, Simone Sanna, Nini Pryds, and Vincenzo \\ Esposito*
}

\begin{abstract}
Cerium oxide (ceria, $\mathrm{CeO}_{2}$ ) is one of the most promising mixed ionic and electronic conducting materials. Previous atomistic analysis has covered widely the effects of substitution on oxygen vacancy migration. However, an in-depth analysis of the role of cation substitution beyond trivalent cations has rarely been explored. Here, we investigate soluble monovalent $\left(\mathrm{Li}^{+}\right.$, $\left.\mathrm{Na}^{+}, \mathrm{K}^{+}, \mathrm{Rb}^{+}\right)$, divalent $\left(\mathrm{Fe}^{2+}, \mathrm{Co}^{2+}, \mathrm{Mn}^{2+}, \mathrm{Mg}^{2+}, \mathrm{Ni}^{2+}, \mathrm{Zn}^{2+}, \mathrm{Cd}^{2+}, \mathrm{Ca}^{2+}, \mathrm{Sr}^{2+}, \mathrm{Ba}^{2+}\right)$, trivalent $\left(\mathrm{Al}^{3+}, \mathrm{Fe}^{3+}, \mathrm{Sc}^{3+}, \mathrm{In}^{3+}, \mathrm{Lu}^{3+}, \mathrm{Yb}^{3+}, \mathrm{Y}^{3+}, \mathrm{Er}^{3+}\right.$, $\left.\mathrm{Gd}^{3+}, \mathrm{Eu}^{3+}, \mathrm{Nd}^{3+}, \mathrm{Pr}^{3+}, \mathrm{La}^{3+}\right)$ and tetravalent $\left(\mathrm{Si}^{4+}, \mathrm{Ge}^{4+}, \mathrm{Ti}^{4+}, \mathrm{Sn}^{4+}, \mathrm{Hf}^{4+}, \mathrm{Zr}^{4+}\right)$ cation substituents. By combining classical simulations and quantum mechanical calculations, we provide an insight into defect association energies between substituent cations and oxygen vacancies as well as their effects on the diffusion mechanisms. Our simulations indicate that oxygen ionic diffusivity of subvalent cation-substituted systems follows the order $\mathrm{Gd}^{3+}>\mathrm{Ca}^{2+}>\mathrm{Na}^{+}$. With the same charge, a larger size mismatch with $\mathrm{Ce}^{4+}$ cation yields a lower oxygen ionic diffusivity, i.e., $\mathrm{Na}^{+}>\mathrm{K}^{+}, \mathrm{Ca}^{2+}>\mathrm{Ni}^{2+}, \mathrm{Gd}^{3+}>\mathrm{Al}^{3+}$. Based on these trends, we identify species that could tune the oxygen ionic diffusivity: we estimate that the optimum oxygen vacancy concentration $\left(x_{\mathrm{V}_{0}}\right)$ for achieving fast oxygen ionic transport is $2.5 \%$ for $\mathrm{Gd}_{x} \mathrm{Ce}_{1-x} \mathrm{O}_{2-x / 2}, \mathrm{Ca}_{x} \mathrm{Ce}_{1-x} \mathrm{O}_{2-x}$ and $\mathrm{Na}_{x} \mathrm{Ce}_{1-x} \mathrm{O}_{2-3 x / 2}$ at 800 K. Remarkably, such a concentration is not constant and shifts gradually to higher values as the temperature is increased. We find that co-substitutions can enhance the impact of the single substitutions beyond that expected by their simple addition. Furthermore, we identify preferential oxygen ion migration pathways, which illustrate the electro-steric effects of substituent cations in determining the energy barrier of oxygen ion migration. Such fundamental insights into the factors that govern the oxygen diffusion coefficient and migration energy would enable design criteria to be defined for tuning the ionic properties of the material, e.g., by co-doping.
\end{abstract}

\section{Introduction}

Materials based on cerium oxide, (ceria, $\mathrm{CeO}_{2}$ ), have attracted an upsurge of interest due to their versatile nature for applications, as they display fast oxygen ion conductivity, efficient catalysis, and giant electro-chemo-mechanical response..$^{1-5}$

Such fascinating effects originate from extrinsic doping, i.e., unique defect chemistry, where point defects, such as oxygen vacancies, are generated to balance the substitutional cations. Understanding the underlying mechanism that controls ionic transport and diffusion is of particular importance. Maximizing the oxygen ion conductivity of ceria is highly desirable for applications such as solid oxide electrolytes and oxide permeable membranes and has been intensively investigated over the last decades. ${ }^{6-10}$ However, low conductivity is also relevant, since a substantial leakage current can lead to the easy breakdown of electromechanical devices, especially in the high electrical field range, e.g., $\left.>50 \mathrm{kV} \mathrm{cm}^{-1}\right) \cdot{ }^{11-12}$

Department of Energy Conversion and Storage, Technical University of Denmark, Anker Engelunds Vej 411, DK-2800 Kgs. Lyngby, Denmark Email:ivca@dtu.dk(IEC); vies@dtu.dk (VE)

Electronic Supplementary Information (ESI) available: Details for potential parameters; defect equations; energy profile; Mean-Squared Displacements (MSDs); traced trajectories; oxygen ion diffusion in co-substituted systems; Oxygen ion migration. See DOI: 10.1039/x0xx00000x
The oxygen exchange and diffusion properties of $\mathrm{CeO}_{2}$ are typically tuned by substituting $\mathrm{Ce}^{4+}$ cations with trivalent, rare-earth cations to generate a high concentration of oxygen vacancies $\left(\mathrm{V}_{0}^{* *}\right) \cdot{ }^{13}$ Differences in the ionic radii, valence state, and electronic configuration of the substituent cations with $\mathrm{Ce}^{4+}$, can induce repulsive elastic energy and attractive electronic energy between the oxygen vacancy and substituent cations. Such interactions give rise to oxygen vacancy-substituent cation associations, resulting in an ionic conductivity maximum with increasing doping concentration ('volcano-type' behavior). ${ }^{14,} 15$ Extensive experimental and theoretical works have revealed that the ionic conductivity in $\mathrm{CeO}_{2}$ increases with increasing substituent cation radius up to $\mathrm{Gd}^{3+}, \mathrm{Eu}^{3+}$, $\mathrm{Sm}^{3+}$, and $\mathrm{Nd}^{3+}$ but decreases afterwards. ${ }^{16-17}$ Based on Density Functional Theories (DFT) simulations, Andersson et al. ${ }^{18}$ proposed an improvement in the oxygen ion conductivity of $\mathrm{CeO}_{2}$ by introducing a mixture of $\mathrm{Nd}^{3+} / \mathrm{Sm}^{3+}$ or $\mathrm{Pr}^{3+} / \mathrm{Gd}^{3+}$ to balance the attractive and repulsive interactions, thereby reducing the association energies. An alternative approach is to fabricate $\mathrm{CeO}_{2}$ codoped with rare-earth ions $\left(\mathrm{Y}^{3+}, \mathrm{Sm}^{3+}, \mathrm{La}^{3+}\right)$ and alkaline earth ions $\left(\mathrm{Ca}^{2+}, \mathrm{Sr}^{2+}\right)$ to tune the 'effective' ionic radius further and to improve the oxygen ion diffusivity. Pearce and Thangadurai found that $\mathrm{CeO}_{2}$ ceramics co-doped with rare-earth $\left(\mathrm{La}^{3+}, \mathrm{Sm}^{3+}\right)$ and alkaline earth ions $\left(\mathrm{Ca}^{2+}, \mathrm{Sr}^{2+}\right)$ exhibit higher ionic conductivities than those seen in 
singly-doped systems. ${ }^{19}$ According to $\mathrm{Xu}$ et al., ${ }^{20}$ the ionic conductivity of $\mathrm{Ce}_{0.8+x} \mathrm{Y}_{0.2-2 x} \mathrm{Ca}_{\mathrm{x}} \mathrm{O}_{1.9} \quad(\mathrm{x}=0-0.1)$ at $700{ }^{\circ} \mathrm{C}$ initially increased and then decreased as the $\mathrm{Ca}^{2+}$ concentration was increased further $\left(34.2,47.2\right.$ and $19.2 \mathrm{mS} \mathrm{cm}^{-1}$ for $\mathrm{x}=0,0.05$, and 0.1 , respectively).

To date, a systematic and comparative investigation on monovalent $\left(\mathrm{M}^{+}\right)$, divalent $\left(\mathrm{M}^{2+}\right)$, trivalent $\left(\mathrm{M}^{3+}\right)$ and tetravalent $\left(\mathrm{M}^{4+}\right)$ cation-substituted systems is still missing, as investigations on tuning the ionic conductivity beyond trivalent, rare-earth ions-substituted $\mathrm{CeO}_{2}$ are still rare. ${ }^{21-23}$ In particular, the solution energy, the interaction between $\mathrm{M}_{\mathrm{Ce}}^{\prime \prime \prime}, \mathrm{M}_{\mathrm{Ce}}^{\prime \prime}, \mathrm{M}_{\mathrm{Ce}}^{\times}$and $\mathrm{V}_{0}^{*}$ compared with that of $\mathrm{M}_{\mathrm{Ce}}^{\prime}$ (Kröger-Vink notation ${ }^{24}$ for defect centers $\mathrm{M}^{+}, \mathrm{M}^{2+}, \mathrm{M}^{4+}$ and $\mathrm{M}^{3+}$, respectively) and their effects on the oxygen ion diffusion dynamics and mechanisms are not well understood. Interpreting the nature of improved oxygen ion conductivity is further complicated by the fact that $\mathrm{CeO}_{2}$ is often contaminated by $\mathrm{Si}, \mathrm{Al}, \mathrm{Fe}$ and $\mathrm{Mn},{ }^{25,}{ }^{26}$ which often segregate at surfaces and/or grain boundaries. ${ }^{27,} 28$ Therefore, clarifying the influence of such 'unwanted' cations on the ionic conductivity of $\mathrm{CeO}_{2}$-based materials is crucial. Furthermore, although an atomic-scale study on the defect chemistry of $\mathrm{M}^{+}, \mathrm{M}^{2+}$ and $\mathrm{M}^{4+}$ substituted $\mathrm{CeO}_{2}$ is still rare, promising phenomena have been observed in such systems, such as the improved redox properties of $\mathrm{CeO}_{2}-\mathrm{ZrO}_{2}$ by sodium $\left(\mathrm{Na}^{+}\right)$inclusion, ${ }^{29}$ the anomalously large dielectric properties in $\mathrm{Ca}: \mathrm{CeO}_{2}$ ceramics, ${ }^{30}$ the improved $\mathrm{O}_{2}$ uptake in $\mathrm{Cu}^{2+}$-doped $\mathrm{Pr}: \mathrm{CeO}_{2},{ }^{31}$ and the enhanced oxygen storage capacity of $\mathrm{Ce}_{1-x} \mathrm{Ti}_{x} \mathrm{O}_{2} \cdot{ }^{32}$

Herein, we directly investigate the effects of $\mathrm{M}^{+}, \mathrm{M}^{2+}, \mathrm{M}^{3+}$, and $\mathrm{M}^{4+}$ cations on oxygen ion migration in $\mathrm{CeO}_{2}$ through atomistic simulations, at the classical and quantum mechanical levels. We first investigated the solution energy of $\mathrm{M}^{+}, \mathrm{M}^{2+}, \mathrm{M}^{3+}$, and $\mathrm{M}^{4+}$ cations in $\mathrm{CeO}_{2}$ and the association energy between the substituent cation and $\mathrm{V}_{0}:$ by molecular statics (MS) lattice simulations. Using molecular dynamics (MD) simulations, we calculated the oxygen tracer diffusion coefficient $\left(D_{O}^{*}\right)$ and the migration energy $\left(E_{\mathrm{mig}}\right)$. Finally, we calculated oxygen migration with various diffusion pathways by a detailed Nudged-Elastic-Band (NEB) method, ${ }^{33}$ in the framework of DFT.

(a)

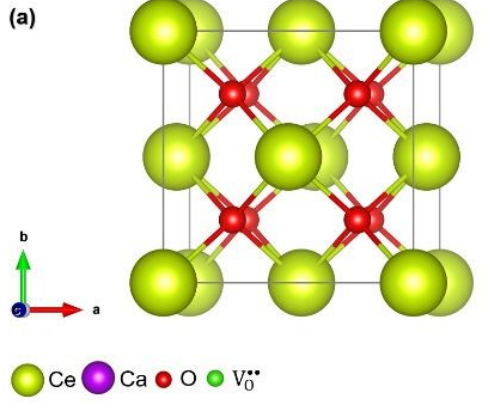

Fig. 1 (a) Cubic fluorite-structured lattice of $\mathrm{CeO}_{2}$; (b) local coordination of $\mathrm{Ce}^{4+}$ cation; (c) local structure of one $\mathrm{Ca}^{2+}$ cation with an oxygen vacancy at the nearest-neighboring site. Colors: $\mathrm{Ce}^{4+}$, yellow; dopant cation, purple; oxygen, red; oxygen vacancy, green.

\section{Computational methods}

View Article Online DOI: 10.1039/DOCP03298K

Classical simulations. Here, the interatomic forces are described using long-range Coulombic forces and Buckingham pair-potentials:

$$
V_{i j}=\frac{Z_{i} Z_{j}}{4 \pi \varepsilon_{0} r_{i j}}+A_{i j} \exp \left(-\frac{r_{i j}}{\rho_{i j}}\right)-\frac{C_{i j}}{r_{i j}^{6}}
$$

where $r_{i j}$ is the distance between ions $i$ and $j, Z_{i(j)}$ are the ion's valences, $\varepsilon_{0}$ is the permittivity of free space, and the parameters $A_{i j}$, $\rho_{i j}$ and $C_{i j}$ are the empirical Buckingham pair-potentials (the list of parameters is reported in the Supplementary Information, Table S1). The ionic polarizability of the ions is described using the shell model, and a harmonic spring is used to attach the massless shell with the ionic core. ${ }^{34}$

The defect energies are calculated by static lattice simulations using the Mott-Littleton approach, ${ }^{35}$ as implemented within the GULP code. $^{36}$ We can thus summarize the defect energy $\left(E_{\text {def }}\right)$ with the following equation: ${ }^{36}$

$$
E_{d e f}=E_{I}(x)+E_{I I A}(x, y)+E_{I I B}(y)
$$

where ionic coordinates and dipole moments determine $E_{1} ; E_{\| \mathrm{AA}}$ is the interaction between region I and region II (interfacial region); and $E_{\mathrm{IIB}}$ is determined by the displacements $(y)$ in region IIA. Here we set the radii for regions I and II at 11 and $22 \AA$, respectively.

We calculated the binding energies ( $\left.E_{\text {bind }}\right)$ of defect clusters, comprised of aliovalent/isovalent cations and oxygen vacancies, using the general relation:

$$
E_{\text {bind }}=E_{\text {associate }}-\left(E_{\text {isolated cation }}+E_{\text {isolated vacancy }}\right)
$$

where $E_{\text {associate }}, E_{\text {isolated cation }}$ and $E_{\text {isolated vacancy }}$ are the defect energy values of the defect cluster, the isolated aliovalent/isovalent cations and the isolated oxygen vacancy, respectively. A negative $E_{\text {bind }}$ indicates an attractive interaction between the substituent cations and the oxygen vacancy. We report the details for the defect reaction and the calculation of the solution energy $\left(E_{\text {sol }}\right)$ in Supplementary Information (section 3).

All ions were treated as rigid ions (omitting the shell model) for the MD simulations. We controlled the temperature by a NoséHoover thermostat with a significant time scale on which $P / T$ is relaxed ( 0.5 and 0.2 for $P_{\text {damp }}$ and $T_{\text {damp, }}$ respectively), as implemented in the LAMMPS package. ${ }^{37-39}$ We introduced the oxygen vacancies by randomly removing oxygen ions and compensated for them by lowering the charge of all $\mathrm{Ce}^{4+}$ to 3.96 for the 'pure' system $\left(\mathrm{Ce}_{4000}^{3.96+} \mathrm{O}_{7920}^{2-}\right)$ and for the $\mathrm{M}^{4+}$-substituted systems $\left(\mathrm{Ce}_{3840}^{3.96+} \mathrm{M}_{160}^{4+}\right.$ $\left.\mathrm{O}_{7920}^{2} 0\right)$, or by acceptor cations, i.e., $\mathrm{M}^{+}\left(\mathrm{Ce}_{4000-{ }_{\mathrm{x}}}^{4+} \mathrm{M}_{\mathrm{x}}^{+} \mathrm{O}_{8000-3 \mathrm{x} / 2}^{2-}\right)$, $\mathrm{M}^{2+}\left(\mathrm{Ce}_{4000-\mathrm{x}}^{4+} \mathrm{M}_{\mathrm{x}}^{2+} \mathrm{O}_{8000-\mathrm{x}}^{2-}\right)$, and $\mathrm{M}^{3+}\left(\mathrm{Ce}_{4000-\mathrm{x}}^{4+} \mathrm{M}_{\mathrm{x}}^{3+} \mathrm{O}_{8000-\mathrm{x} / 2}^{2-}\right)$. At each temperature, the MD simulations were first equilibrated for at least 600 ps at constant pressure (NPT ensemble), followed by a production run for $600 \mathrm{ps}$ in a NVT ensemble.

Quantum mechanical calculations. DFT calculations were performed using the Quantum Espresso code. ${ }^{40}$ The general gradient approximation (GGA) was used according to the Perdew-BurkeErnzerhof (PBE) functional to describe the exchange-correlation interaction (the Standard Solid State Pseudopotential, SSSP precision libraries). ${ }^{41}$ We applied a Hubbard $U$ parameter of $5.0 \mathrm{eV}$ on cerium, as recommended by Castleton et al. ${ }^{42}$ We achieved convergence of the geometry and lattice energy with the cut-off energy of the planewave basis set and electronic density being 100 and 800 Ry, respectively. A comparison of the lattice parameters calculated with 
various methods is reported in Table S2. A $2 \times 2 \times 2$ supercell of the fluorite structure (96 atoms) was used, with structure optimization using a $2 \times 2 \times 2$ Monkhorst-Pack k-point grid. For the defect calculations, relaxation of the ion positions was conducted until the

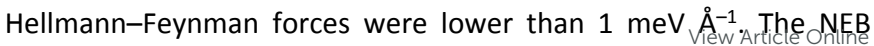

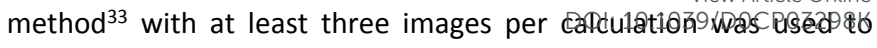
obtain energy barriers and reaction paths (gamma point only).
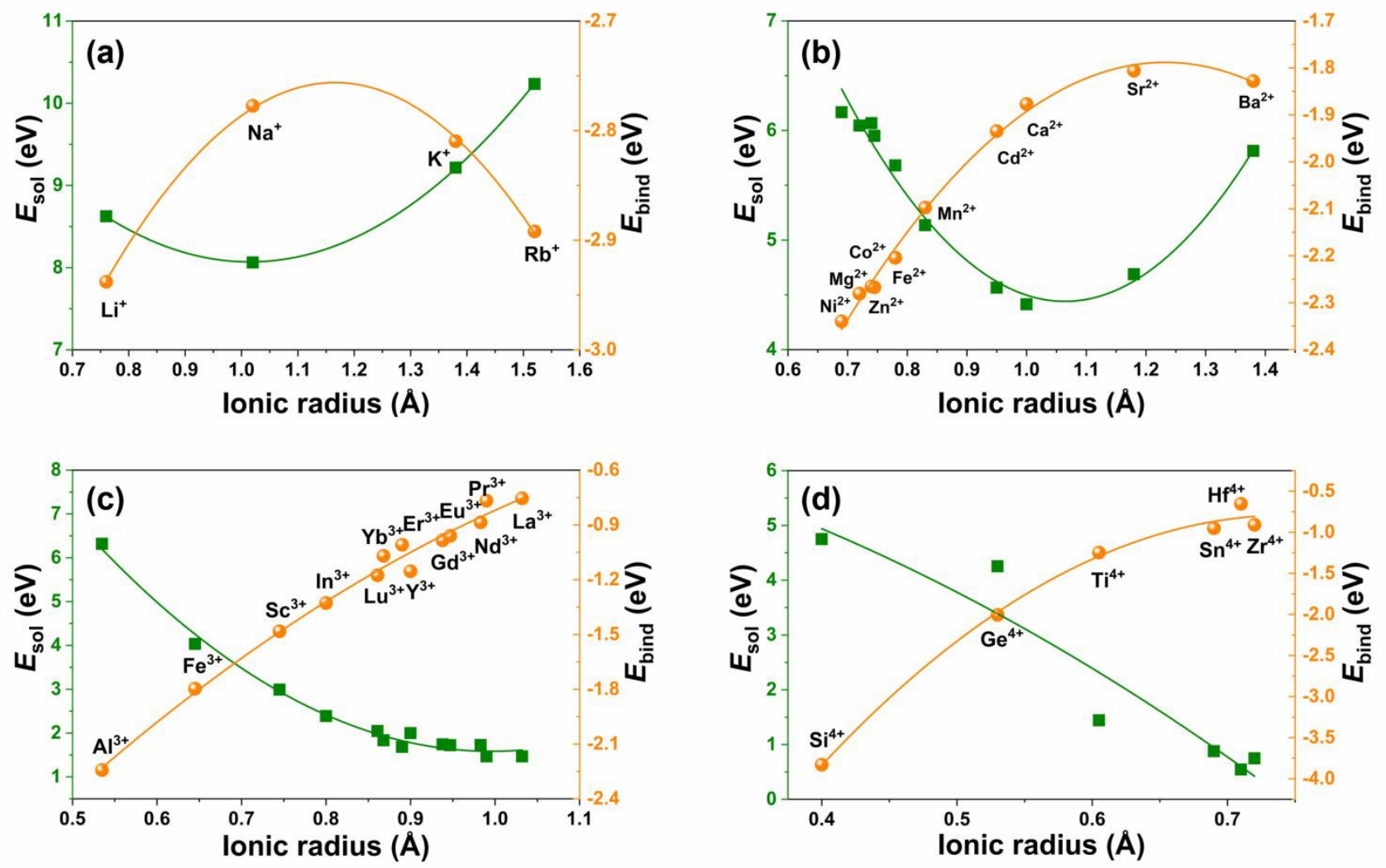

Fig. 2 Solution energy and binding energy of (a) $\mathrm{M}^{+}$; (b) $\mathrm{M}^{2+}$; (c) $\mathrm{M}^{3+}$ and (d) $\mathrm{M}^{4+}$ cations in $\mathrm{CeO}_{2}$ calculated by $\mathrm{MS}$ simulations. Since the ionic radii for eightcoordination values are not available for all of the ions considered, the values for six-coordination from Shannon ${ }^{43}$ are used. For cations with a magnetic moment, the values for high-spin ionic radius are used. ${ }^{43}$ The lines are used to guide the eyes only.

\section{Results and discussion}

To have a clear picture of the oxygen ion migration in various substituted $\mathrm{CeO}_{2}$ instances, we investigate the key factors governing the association energy of oxygen vacancies with the cation defects incorporated. Firstly, we examined the trend of ion size for solution energy and association energy between the substituent cations and oxygen vacancies. Secondly, we examined the oxygen diffusion dynamic behavior of systems substituted with typical cations, which reveals the energetics for un-bounding the substituent cation-oxygen vacancy defect clusters. Thirdly, we examined the oxygen ion diffusion mechanisms to clarify the effects of size and charge of the substituent cations upon oxygen vacancy migration.

\subsection{Defect energy}

Fig. 1a represents the $\mathrm{CeO}_{2}$ lattice with its centrosymmetric fluorite structure, where eight oxygen anions $\left(\mathrm{Ce}^{4+}-8 \mathrm{O}\right.$ configuration) surround each cerium. Fig. 1b shows the local environment of $\mathrm{Ce}^{4+}$ cations, whereas Fig. 1c presents the local structure of a substituent cation together with an oxygen vacancy at its nearest-neighboring site (70- $\mathrm{Ca}_{\mathrm{Ce}}^{\prime \prime}-\mathrm{V}_{0}$ configuration).
We first investigated the solution energy $\left(E_{\text {sol }}\right)$ and binding energy $\left(E_{\text {bind }}\right)$ values of various cations. Fig. 2a shows that the radii of the $\mathrm{M}^{+}$cations have little effect on the solution energies and binding energies. The considerable solution energies of the monovalent cations suggest a low solution limit of such cations in $\mathrm{CeO}_{2}$, due to the significant charge difference between them and $\mathrm{Ce}^{4+}$ cation. The similar size of $\mathrm{Na}^{+}(1.02 \AA)$ to $\mathrm{Ce}^{4+}(0.98 \AA)^{43}$ results in the most favorable solution energy and the weakest interaction between $\mathrm{Na}_{\mathrm{Ce}}^{\prime \prime \prime}$ and $\mathrm{V}_{0}^{\bullet \bullet}$ for the alkali metal cations. Likewise, there is a high correlation between the solution energy, the binding energy, and the size of the $\mathrm{M}^{2+}$ cations (Fig. 2b). The reduced solution energies (ranging from 6.17 to $4.41 \mathrm{eV}$ ) suggest a higher solution limit than that for the monovalent cations. We expect that transition metals $\mathrm{Fe}^{2+}, \mathrm{Co}^{2+}, \mathrm{Mn}^{2+}, \mathrm{Mg}^{2+}, \mathrm{Ni}^{2+}$, and $\mathrm{Zn}^{2+}$ will act as significant trapping centers for oxygen vacancies due to their considerable binding energies (the magnitude of $E_{\mathrm{bind}}>2$ $\mathrm{eV}$ ). The relatively low solution energies and the weak binding energies for $\mathrm{Ca}^{2+}$ and $\mathrm{Sr}^{2+}$ suggest that such cations are promising for the development of oxygen ion conductors as they will not exert a strong trapping effect on the oxygen vacancies. 
For trivalent cations, size plays an essential role in determining the defect energy: the solution energy as well as the magnitude of the binding energy show a monotonic decrease with an increase of the ionic radius (Fig. 2c). The relatively large binding energies for $\mathrm{Al}^{3+}$ and $\mathrm{Fe}^{3+}$ indicate a strong interaction of $\mathrm{Al}_{\mathrm{Ce}}^{\prime}$ and $\mathrm{Fe}_{\mathrm{Ce}}^{\prime}$ with $\mathrm{V}_{0}^{\circ}$, which is attributed to the significant size mismatch with $\mathrm{Ce}^{4+}$ in addition to the charge difference. Although there are limited experimental data about $\mathrm{Al}_{\mathrm{Ce}}^{\prime}$ and $\mathrm{Fe}_{\mathrm{Ce}}^{\prime}$ for direct comparison, Nuclear Magnetic Resonance spectroscopic studies on ${ }^{45} \mathrm{SC}$ and ${ }^{89} \mathrm{Y}$ have revealed that all oxygen vacancies in the lattice are associated with ${ }^{45} \mathrm{Sc}$ or ${ }^{89} \mathrm{Y}$ atoms at the nearest neighboring site. ${ }^{44,} 45$ The weak attractive interaction between large rare-earth cations (i.e., $\mathrm{Gd}^{3+}, \mathrm{Eu}^{3+}, \mathrm{Pr}^{3+}$, and $\mathrm{Nd}^{3+}$ ) and oxygen vacancies confirms that such cations are promising for the improvement of oxygen ion diffusivity, which is in line with previous experimental and theoretical studies. ${ }^{9,17}$ Unlike $\mathrm{M}^{+}, \mathrm{M}^{2+}$, and $\mathrm{M}^{3+}$ cations, the incorporation of $\mathrm{M}^{4+}$ cations will not introduce extrinsic oxygen vacancies. Therefore, such cations have rather low solution energies and are predicted to have a high solubility (Fig. 2d). This is consistent with the fact that $\mathrm{CeO}_{2}$ can form solutions with $\mathrm{SiO}_{2}, \mathrm{TiO}_{2}$, and $\mathrm{ZrO}_{2}$ over a wide composition range. ${ }^{46,47}$ The magnitude of the binding energy increases with an increase in the size mismatch, and the maximum value observed is for $\mathrm{Si}^{4+}$. Such results demonstrate the importance of elastic strain effects, indicating that $\mathrm{M}^{4+}$ cations prefer 7-fold coordination by oxygen ions, in contrast to the usual 8-fold coordination of $\mathrm{Ce}^{4+}$ cations in $\mathrm{CeO}_{2}$.

\subsection{Oxygen ion diffusion}

The macroscopic oxygen ionic conductivity involves complex oxygen ionic-jump processes: the oxygen ion jumps around the defect center(s), the oxygen ion jumps away and towards the defect center(s), etc. We thus investigate the oxygen ion diffusion further by MD simulations with large supercells, which can take account of various possible jumps of the oxygen vacancies. We focus on typical cations, i.e., cations which show the weakest interactions (e.g. $\mathrm{Na}^{+}, \mathrm{Ca}^{2+}, \mathrm{Gd}^{3+}$, and $\mathrm{Zr}^{4+}$, 'weak set') and the strongest interactions (e.g., $\mathrm{K}^{+}, \mathrm{Ni}^{2+}, \mathrm{Al}^{3+}$, and $\mathrm{Si}^{4+}$, 'strong set') with oxygen vacancies within $\mathrm{M}^{+}, \mathrm{M}^{2+}, \mathrm{M}^{3+}$, and $\mathrm{M}^{4+}$ predicted by $\mathrm{MS}$ simulations. We do not consider $\mathrm{Li}^{+}$and $\mathrm{Rb}^{+}$due to their high mobility and low solution limit, respectively. Moreover, we select $\mathrm{Ca}^{2+}$ rather than $\mathrm{Sr}^{2+}$ for the following reasons: (1) $\mathrm{Ca}^{2+}$ has a higher solution limit; (2) $\mathrm{Ca}^{2+}(1.0 \AA)$ has a similar size to $\mathrm{Na}^{+}(1.02$ $\AA$ ) and $\mathrm{Gd}^{3+}(0.94 \AA) ; 43$ and (3) because of the easy formation of the $\mathrm{SrCeO}_{3}$ secondary phase within $\mathrm{Sr}^{2+}$ cation-substituted $\mathrm{CeO}_{2} \cdot{ }^{48}$

Fig. $3 a$ and $b$ show the oxygen tracer diffusion coefficients $\left(D_{0}^{*}\right)$ as a function of inverse temperature as well as the migration energies $\left(E_{\text {mig }}\right)$ for oxygen vacancies obtained by MD simulations. We obtained the highest diffusion coefficient at any given temperature for the 'pure' system. This confirms the clustering of substituent cations with oxygen vacancies, which is consistent with the negative binding energies obtained by MS simulations (Fig. 2). Our results reveal that the migration energies of subvalent cation-substituted systems within the 'weak set' follow the order $\mathrm{Gd}^{3+}>\mathrm{Ca}^{2+}>\mathrm{Na}^{+}$(e.g., 0.88, 1.02 and $1.18 \mathrm{eV}$ ), whereas within the 'strong set' the migration energies are very close to each other (e.g., $\approx 1.30 \mathrm{eV}$ ). The migration energy increases significantly, from $0.68 \mathrm{eV}$ for the 'pure' system to $31.070 \mathrm{eV}$ forpthé $\mathrm{Zr}^{4+}$-substituted system. We can also note that the $\mathrm{Si}^{4+}$ substituted system exhibits the highest migration energy $(1.57$ $\mathrm{eV}$ ) among all the systems investigated, as is consistent with the largest association energy between $\mathrm{Si}_{\mathrm{Ce}}^{\times}$and the oxygen vacancy obtained by MS calculations (Fig. 2d).
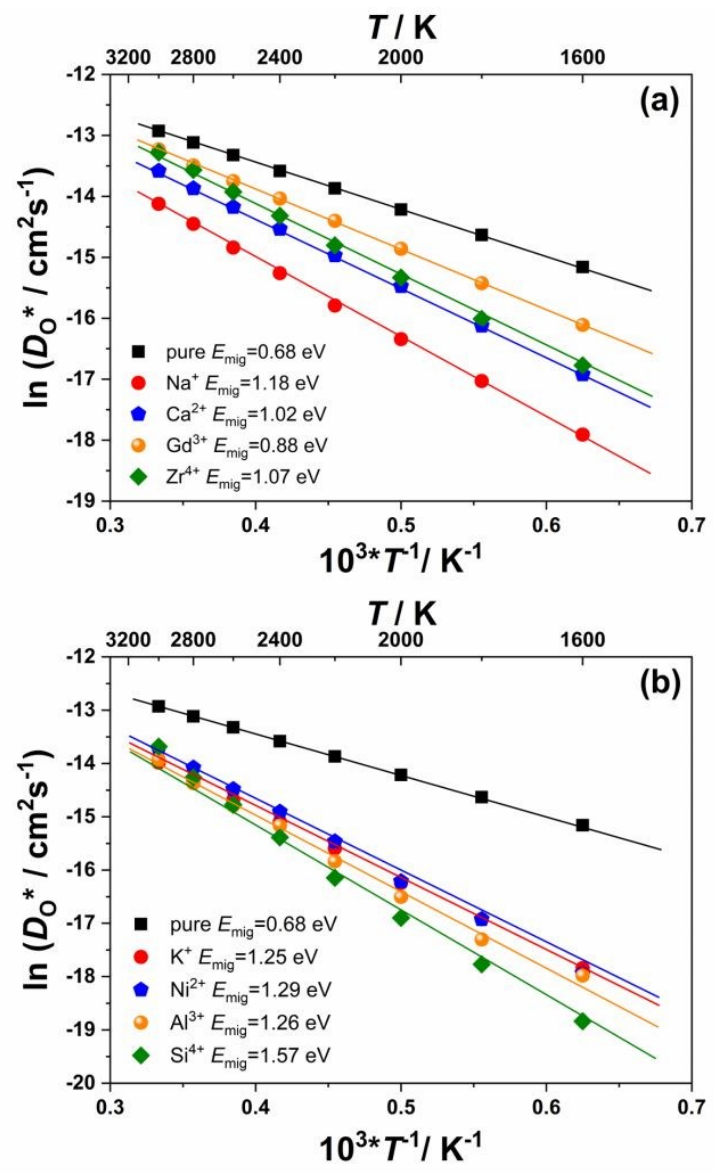

Fig. 3. Oxygen tracer diffusion coefficients $\left(D_{O}^{*}\right)$ as a function of inverse temperature for systems substituted with (a) $\mathrm{Na}^{+}, \mathrm{Ca}^{2+}, \mathrm{Gd}^{3+}$, and $\mathrm{Zr}^{4+}$ and (b) $\mathrm{K}^{+}, \mathrm{Ni}^{2+}, \mathrm{Al}^{3+}$, and $\mathrm{Si}^{4+}$. The oxygen vacancy concentration is $1 \%$.

Fig. 4a shows the oxygen tracer diffusion coefficient $\left(D_{0}^{*}\right)$ as a function of the $\mathrm{Ca}^{2+}$ concentration. With the increase of $\mathrm{Ca}^{2+}$ concentration $(x)$, the migration energy decreases slightly from 1.02 to $1.01 \mathrm{eV}$ and then increases almost linearly to $1.27 \mathrm{eV}$ for $x=7.5 \%$. Oxygen tracer diffusion coefficients as a function of oxygen vacancy concentration $\left(x_{V_{0}^{*}}\right)$ for $\mathrm{Gd}_{x} \mathrm{Ce}_{1-x} \mathrm{O}_{2-x / 2}, \mathrm{Ca}_{x} \mathrm{Ce}_{1-x} \mathrm{O}_{2-}$ $x$ and $\mathrm{Na}_{x} \mathrm{Ce}_{1-x} \mathrm{O}_{2-3 x / 2}$ are extrapolated to experimentally relevant temperatures and are summarized in Fig. 4b, c and d, respectively. For all the systems the values of $D_{0}^{*}$ show a typical increase and then a decrease with increasing $x_{V_{0}^{*}}$. The decrease is attributed to the trapping of oxygen vacancies by defect centers. At $800 \mathrm{~K}$, we can observe a $D_{0}^{*}$ maximum at $x_{\mathrm{V}_{0}^{*}} \approx 2.5 \%$ for all systems investigated, corresponding to a concentration of $\mathrm{Gd}^{3+}$, $\mathrm{Ca}^{2+}$ and $\mathrm{Na}^{+}$being 10, 5 and 3.3\%, respectively. The magnitude of $D_{0}^{*}$ varies by two orders of magnitude and follows the order $\mathrm{Gd}_{0.1} \mathrm{Ce}_{0.9} \mathrm{O}_{1.95}>\mathrm{Ca}_{0.05} \mathrm{Ce}_{0.95} \mathrm{O}_{1.95}>\mathrm{Na}_{0.03} \mathrm{Ce}_{0.97} \mathrm{O}_{1.95}$. With 
increasing temperature, the optimum $x_{V_{0}^{*}}$ slightly shifts to a higher value as overcoming the associating interactions becomes easier at higher temperatures.

Co-substituting two cation species is a promising approach for combining the positive effects of the substitution of single cations, that is beyond a mere additive effect. ${ }^{18-20}$ Fig. S3 shows the oxygen ion diffusion behavior of the $\mathrm{Gd}^{3+} / \mathrm{Ca}^{2+}, \mathrm{Nd}^{3+} / \mathrm{Ca}^{2+}$ and $\mathrm{Lu}^{3+} / \mathrm{Ca}^{2+}$ co-substituted systems. We here fix the oxygen vacancy concentration $\left(x_{V_{0}^{*}}\right)$ at $2.5 \%$ for ease of comparison. The $\mathrm{Gd}^{3+} / \mathrm{Ca}^{2+}$ and $\mathrm{Nd}^{3+} / \mathrm{Ca}^{2+}$ co-substitutions facilitate the oxygen ion
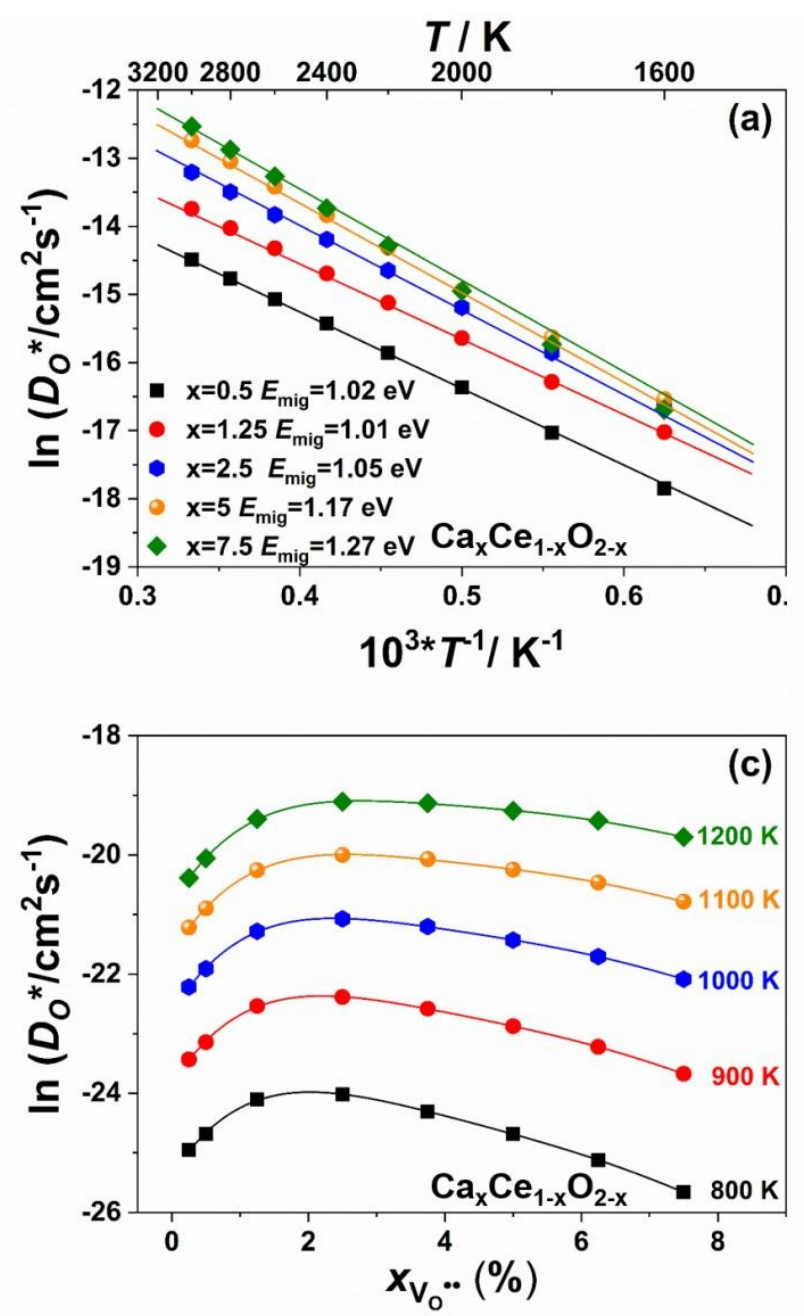

diffusion and yield slightly higher tracer diffusion coefficieients

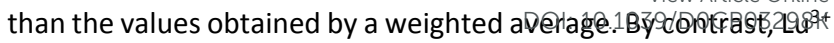
and $\mathrm{Ca}^{2+}$ co-substitution give rise to a significantly reduced $D_{0}^{*}$, indicating an enhanced association interactions between the defect clusters and the oxygen vacancies. Whereas such an association is detrimental for ionic conductivity it is desirable for electromechanical applications. Several experimental evidences indicate that oxygen ion blocking barriers can improve the electrostriction effect in ceria solutions. ${ }^{12,49}$
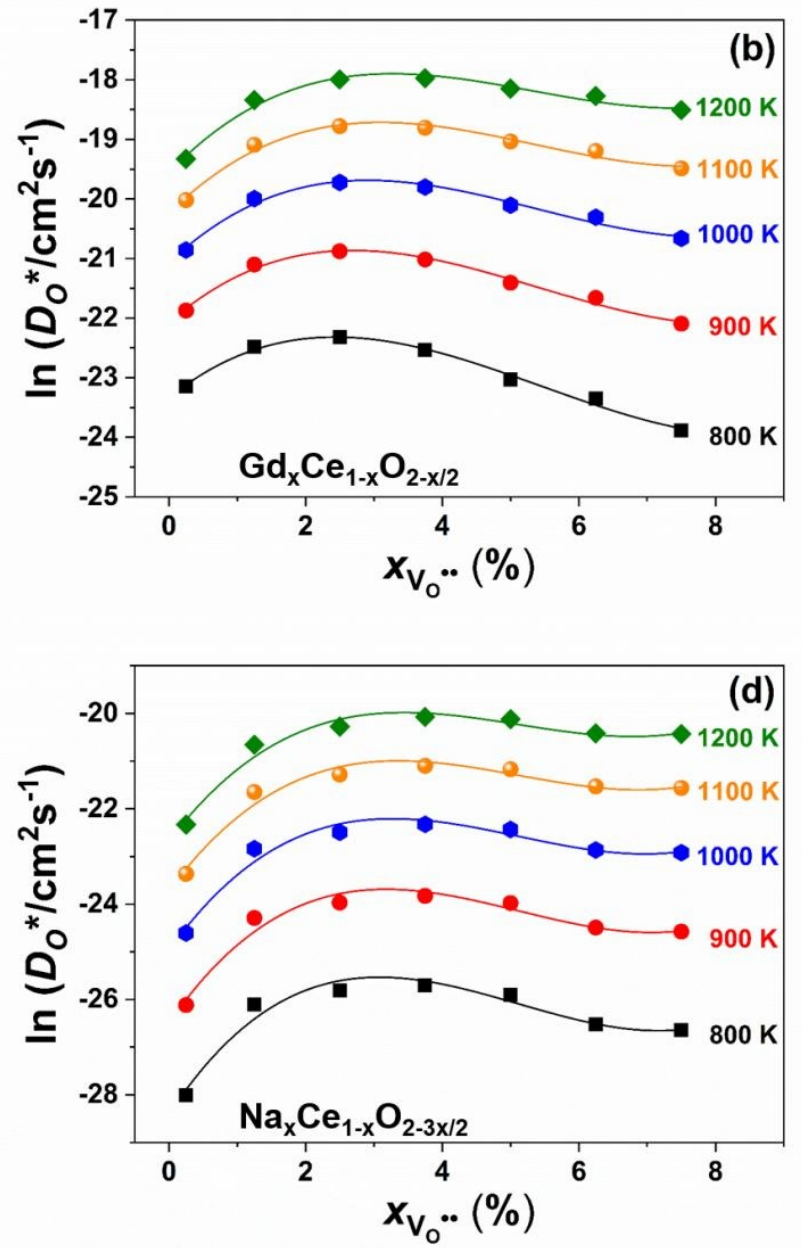

Fig. 4. (a) Oxygen tracer diffusion coefficients $\left(D_{0}^{*}\right)$ as a function of inverse temperature for $\mathrm{CeO}_{2}$ substituted by different $\mathrm{Ca}^{2+}$ concentrations. Oxygen vacancy concentration $\left(x_{V_{0}^{*}}\right)$ dependence of $D_{0}^{*}$ for (b) $\mathrm{Gd}_{x} \mathrm{Ce}_{1-x} \mathrm{O}_{2-x / 2} ;$ (c) $\mathrm{Ca}_{x} \mathrm{Ce}_{1-x} \mathrm{O}_{2-x}$ (d) $\mathrm{Na}_{x} \mathrm{Ce}_{1-x} \mathrm{O}_{2-3 x / 2 .} x$ in (a) corresponds to the $\mathrm{Ca}^{2+}$ cation concentration. 


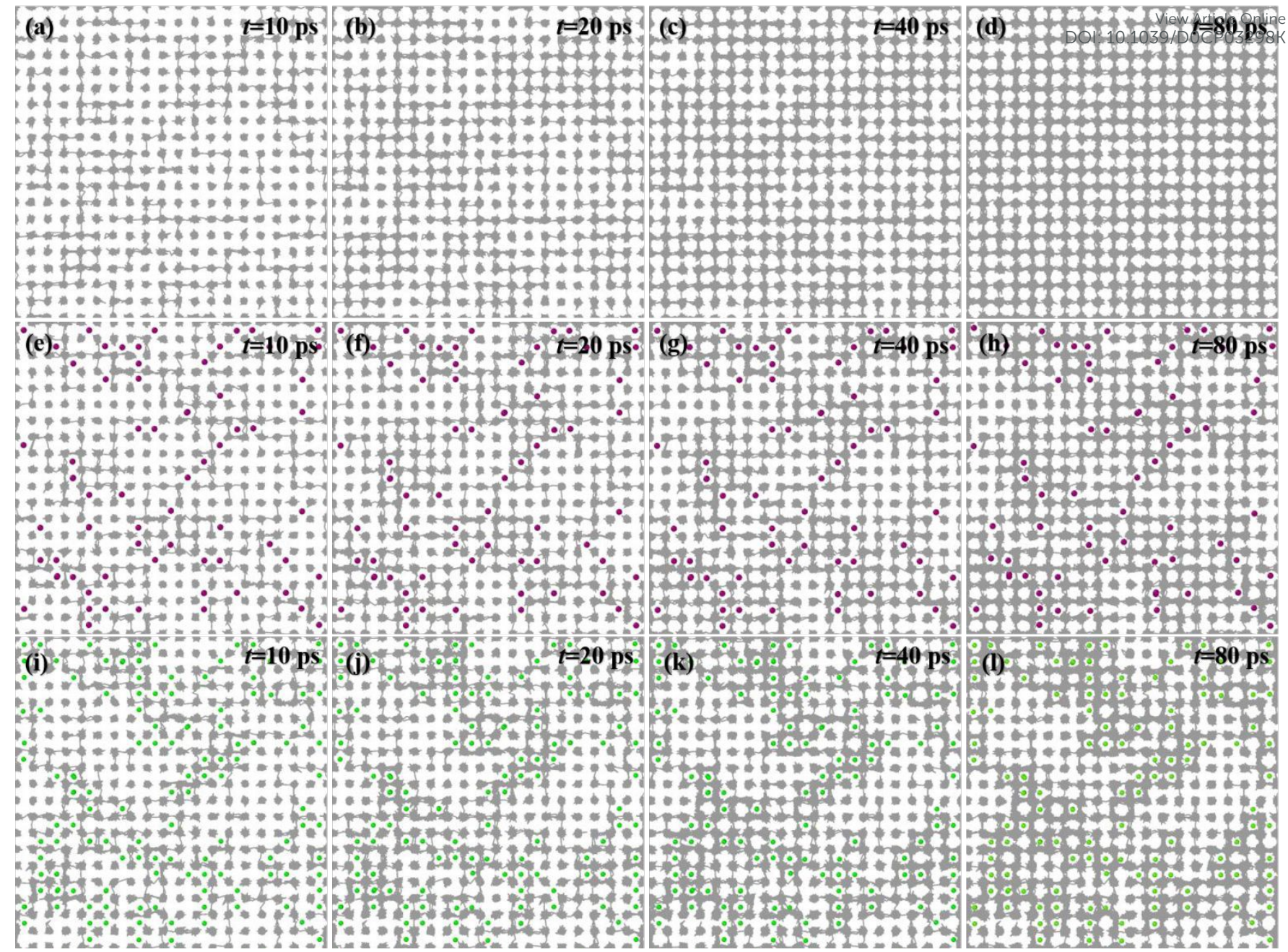

Fig. 5 Traced trajectories for oxygen ion diffusion of 'pure' system (a)-(d); $\mathrm{Ca}^{2+}$ substituted system (e)-( $\mathrm{h}$ ); $\mathrm{Si}^{4+}$ substituted system (i)-(l) as a function of time at $2400 \mathrm{~K}$ projected onto the $a b$ plane. The $\mathrm{Ce}^{4+}$ and $\mathrm{O}^{2-}$ ions are omitted for clarity. Note that the radii of the cations do not correspond to their real size. Colors: $\mathrm{Ca}^{2+}$, purple; $\mathrm{Si}^{4+}$, green.

Table 1. Energy barrier for blocking $\left(E_{\text {block, }}, \mathrm{eV}\right)$ and trapping $\left(E_{\text {trap, }}, \mathrm{eV}\right)$ mechanisms for oxide-ion migration with various diffusion pathways. The values for $E_{\text {trap }}$ correspond to an oxygen ion jumping from the nearest-neighboring site to the next nearest-neighboring site, whereas the values in the brackets correspond to the reverse process. Energy difference $\left(E_{\text {diff, }}, \mathrm{eV}\right)$ of $E_{\text {trap }}$ compared to the oxygen ion migration within pure $\mathrm{CeO}_{2}$. The effects of charge were examined by fixing the lattice configurations (oxygen ion migration with the presence of a $\mathrm{Ca}_{\mathrm{Ce}}^{\prime \prime}$ defect center), but replacing the $\mathrm{Ca}_{\mathrm{Ce}}^{\prime \prime}$ with $\mathrm{Na}_{\mathrm{Ce}}^{\prime \prime \prime}\left(\mathrm{Na}^{+} / \mathrm{Ca}^{2+*}\right), \mathrm{Gd}_{\mathrm{Ce}}^{\prime}\left(\mathrm{Gd}^{3+} / \mathrm{Ca}^{2+*}\right)$ or $\mathrm{Ce}_{\mathrm{Ce}}^{\times}\left(\mathrm{Ce}^{4+} / \mathrm{Ca}^{2+*}\right)$. In this approach, only the relaxation of the migrating oxygen ion is allowed to reduce the steric hindrance.

\begin{tabular}{cccccccccc}
\hline & $\mathrm{Cd}^{2+}$ & $\mathrm{Ca}^{2+}$ & $\mathrm{Sr}^{2+}$ & $\mathrm{Na}^{+}$ & $\mathrm{Gd}^{3+}$ & \multicolumn{2}{c}{$\mathrm{Na}^{+} / \mathrm{Ca}^{2+*}$} & $\mathrm{Gd}^{3+} / \mathrm{Ca}^{2+*}$ & $\mathrm{Ce}^{4+} / \mathrm{Ca}^{2+*}$ \\
\hline$E_{\text {block }}$ & 0.67 & 0.75 & 1.09 & 0.88 & 0.65 & 0.60 & 1.02 & 0.78 \\
$E_{\text {trap }}$ & $0.16(0.78)$ & $0.27(0.58)$ & $0.35(0.54)$ & $0.18(0.72)$ & $0.53(0.66)$ & $0.13(0.68)$ & $0.37(0.44)$ & $0.75(0.76)$ \\
$E_{\text {diff }}$ & $-0.37(0.25)$ & $-0.26(0.05)$ & $-0.18(0.10)$ & $-0.35(0.19)$ & $0(0.13)$ & $-0.40(0.15)$ & $-0.16(-0.09)$ & $0.22(0.23)$ \\
\hline
\end{tabular}

*Oxygen ion diffusion with a fixed initial-, final- and saddle-point configuration of $\mathrm{Ca}_{\mathrm{Ce}}$

\subsection{Traced trajectories}

To better visualize the diffusion pathways and all positions in the lattice traversed as a function of time, we produce the traced trajectories for oxygen ion diffusion as a function of time at $T=2400$ $\mathrm{K}$ (Fig. 5). As expected, the 'pure' system exhibits significant longrange, three-dimensional oxygen ion diffusion. The isotropic and homogeneous traced trajectories demonstrate that the oxygen ion follows a three-dimensional random walk behavior. From the traced migration paths shown in Fig. $5 \mathrm{e}-\mathrm{l}$, it is evident that the substituting defects will act as trapping centers for oxygen vacancies, making the oxygen vacancies 'rattle around' such defect centers. This effect certainly reduces the number of 'free' oxygen vacancies available for migration. Therefore, the long-range diffusion of oxygen ions is significantly restricted and the $D_{0}^{*}$ value decreases in aliovalent/isovalent cation-substituted $\mathrm{CeO}_{2}$ systems. It is worth mentioning here that the oxygen vacancies in our systems are generated by randomly removing the oxygen ions from the lattice sites. The traced trajectories for $\mathrm{Ca}^{2+}$ cation substituted materials 
show evident enrichment around such cation defects as a function of time. Therefore, the substituting defect centers will not only affect the energy barriers for oxygen ion diffusion but will also affect the distribution of oxygen vacancies within the crystal lattice. This configuration is also the case for $\mathrm{Si}^{4+}$ cations, but with a much more profound effect (Fig. 5c). A comparison of the traced trajectories for $\mathrm{Na}^{+}$cation-substituted systems and $\mathrm{K}^{+}$-substituted ones reveals that (see Fig. S4) the $\mathrm{K}^{+}$cations would reduce the channels for the smooth movement of oxygen ions around the $\mathrm{K}_{\mathrm{Ce}}^{\prime \prime \prime}$ defect centers, which is related to their larger ionic size.
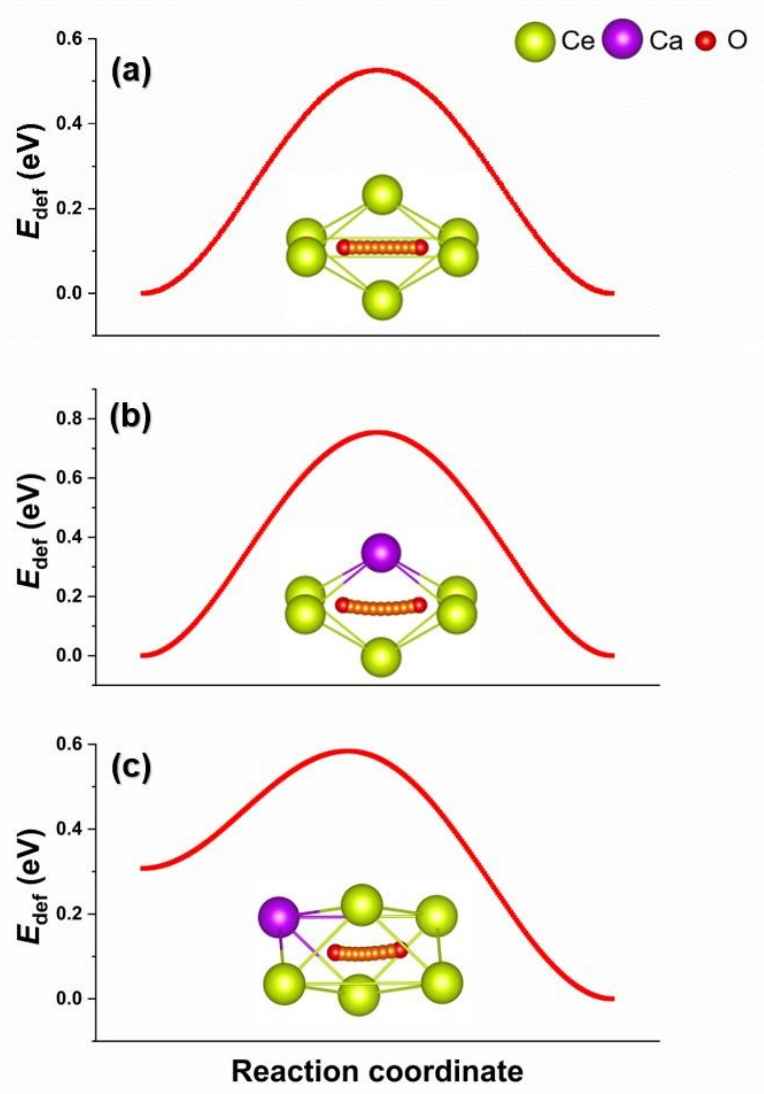

Fig. 6 Defect site energy as a function of the reaction coordinate for oxygen ion migration with various migration edges: (a) within pure $\mathrm{CeO}_{2}$; (b) from one nearest-neighboring site to another nearestneighboring site of $\mathrm{Ca}_{\mathrm{Ce}}^{\prime \prime}$ ( $\mathrm{c}$ ) from the nearest-neighboring site to the next nearest-neighboring site of $\mathrm{Ca}_{\mathrm{Ce}}^{\prime \prime}$ and vice versa. The insets are the traced trajectories, which show that the oxygen ion follows a linear pathway in (a), but a slightly curved pathway in (b) and (c). The energy profile for (c) corresponds to an oxygen ion migrating from the left side to the right side (with the oxygen vacancy direction from the right side to the left side). Colors: $\mathrm{Ce}^{4+}$, yellow; $\mathrm{Ca}^{2+}$ cation, purple; oxygen, red.

\subsection{Oxygen ion migration energy}

As shown in Fig. 6a, the most favourable pathway within pure $\mathrm{CeO}_{2}$ for an oxygen ion to migrate is linearly along the (100) direction, with an energy barrier of $0.53 \mathrm{eV}$. This agrees well with the results obtained by MS simulations ( $0.59 \mathrm{eV}$, Fig. S1). Fig. $6 \mathrm{~b}$ and c exhibit the 'blocking mechanism' $\left(E_{\text {block}}\right)$ and 'trapping mechanism' $\left(E_{\text {trap }}\right)$, 50,
51 respectively, of $\mathrm{Ca}_{\mathrm{Ce}}^{\prime \prime}$ on the migrating oxygen ion, i. Genthe the oxygen ion migrates from one nearest-neighboring site to bnother Rearestneighboring site (blocking); and from the nearest-neighboring site to the next nearest-neighboring site and vice versa (trapping). For the former migration mechanism (Fig. 6b), the presence of $\mathrm{Ca}_{\mathrm{Ce}}^{\prime \prime}$ yields a slightly curved pathway with the saddle-point deviating away from $\mathrm{Ca}_{\mathrm{Ce}}^{\prime \prime}$, and an increase of the energy barrier to $0.75 \mathrm{eV}$. For the latter migration mechanism (Fig. 6c), the trapping of oxygen vacancy by $\mathrm{Ca}_{\mathrm{Ce}}^{\prime \prime}$ results in an asymmetric energy profile, with the migration energy for the vacancy jump away from the associating $\mathrm{Ca}_{\mathrm{Ce}}^{\prime \prime}(0.58$ $\mathrm{eV}$ ) being much higher than for the reverse process $(0.27 \mathrm{eV})$. This is consistent with the high binding energy obtained by MS lattice simulations and confirms that the oxygen vacancy prefers to reside in the nearest-neighboring site of the $\mathrm{Ca}_{\mathrm{Ce}}^{\prime \prime}$.

The effects of the substituent cation's size are analyzed in detail by inspecting the oxygen ion migration along various migration edges, as listed in Table 1. Compared with $\mathrm{Ca}_{\mathrm{Ce}}^{\prime \prime}$, the $\mathrm{Cd}_{\mathrm{Ce}}^{\prime \prime}$ defect center increases the local free volume, which facilitates the oxygen ion migration and thereby reduces the $E_{\mathrm{block}}$ to $0.67 \mathrm{eV}$. By contrast, the $\mathrm{Sr}_{\mathrm{Ce}}^{\prime \prime}$ defect center reduces the free volume for the oxygen ion to jump through the migration aperture. Therefore, the constituent ions should relax substantially to reduce the steric hindrance to allow the jump to take place, thus increasing the energy barrier to $1.09 \mathrm{eV}$. On the other hand, $E_{\text {trap }}$ decreases with an increase of the subvalent cation radius, as in agreement with the results obtained by MS simulations. To identify the effects of charge, we fix the lattice configurations (oxygen ion migration with the presence of a $\mathrm{Ca}_{\mathrm{Ce}}^{\prime \prime}$ defect center), but replace $\mathrm{Ca}_{\mathrm{Ce}}^{\prime \prime}$ by $\mathrm{Na}_{\mathrm{Ce}}^{\prime \prime \prime}, \mathrm{Gd}_{\mathrm{Ce}}^{\prime}$ or $\mathrm{Ce}_{\mathrm{Ce}}^{\times}$(abbreviated as $\mathrm{Na}^{+} / \mathrm{Ca}^{2+*}, \mathrm{Gd}^{3+} / \mathrm{Ca}^{2+*}$, and $\mathrm{Ce}^{4+} / \mathrm{Ca}^{2+*}$, respectively). In this way, only the relaxation of the migrating oxygen ion is allowed to reduce the steric hindrance. The increased $E_{\text {trap }}$ indicates that the interactions between the migrating oxygen ion and the defect center are becoming more and more difficult to overcome as the subvalent cation charge increases. Moreover, the values of $E_{\text {block }}$ follow the trend $\mathrm{Gd}^{3+} / \mathrm{Ca}^{2+*}>\mathrm{Gd}^{3+}>\mathrm{Na}^{+}>\mathrm{Na}^{+} / \mathrm{Ca}^{2+*}$. Therefore, extensive lattice relaxations are involved in the realization of oxygen ion migration, the magnitude of which follows the order $\mathrm{Gd}^{3+}>\mathrm{Ca}^{2+}>$ $\mathrm{Na}^{+}$.

Owning to the significant lattice distortion, the $\mathrm{Ce}^{4+} / \mathrm{Ca}^{2+*}$ system results in a lower nearest-neighboring site energy than the next nearest-neighboring site for oxygen ions, indicating that the oxygen vacancy prefers to locate nearby the $\mathrm{Ce}^{4+} / \mathrm{Ca}^{2+*}$ defect center. Furthermore, the relatively high blocking energy values for the $\mathrm{K}^{+}$ $(1.26 \mathrm{eV})$ and $\mathrm{Ba}^{2+}(1.50 \mathrm{eV})$ cations (Table S3) further demonstrate that this migration is highly unfavorable, which is consistent with traced trajectories observed by MD simulations.

\section{Conclusions}

Based on atomic-scale simulations calculations, we identify useful trends in the defect chemistry and the oxide ion diffusion mechanism in $\mathrm{CeO}_{2}$-based material systems:

1. For subvalent cations of similar size, the higher the charge value, the higher the oxygen diffusivity (i.e. the trend $\mathrm{Gd}^{3+}>\mathrm{Ca}^{2+}>\mathrm{Na}^{+}$is followed) and the weaker the associating interaction between the oxygen vacancies and the dopants. 
2. For isovalent cations, the size mismatch to $\mathrm{Ce}^{4+}$ yields a higher oxygen ionic diffusivity, e.g., the trend $\mathrm{Na}^{+}>\mathrm{K}^{+}, \mathrm{Ca}^{2+}>\mathrm{Ni}^{2+}, \mathrm{Gd}^{3+}>$ $\mathrm{Al}^{3+}$ is followed. More specifically, larger cations block the oxygen ion migration because they reduce the 'free volume' for the movement of the oxygen ions. On the other hand, smaller cations lower the energy barrier for the oxygen vacancy to 'rattle around', which reduces the number of 'free' oxygen vacancies available for ionic conduction. In addition, the magnitude of the binding energies increases with increase in the size mismatch, highlighting the importance of elastic strain effects.

3. To achieve fast oxygen ionic transport the optimum oxygen vacancy concentration is $2.5 \%$ for $\mathrm{Gd}_{x} \mathrm{Ce}_{1-x} \mathrm{O}_{2-x / 2}, \mathrm{Ca}_{x} \mathrm{Ce}_{1-x} \mathrm{O}_{2-x}$ and $\mathrm{Na}_{x} \mathrm{Ce}_{1-x} \mathrm{O}_{2-3 x / 2}$ at $800 \mathrm{~K}$, which is not constant and shifts gradually to higher values with increasing temperature.

4. Co-substitutions can enhance the impact of single substitutions beyond that expected by simple addition.

In addition to identifying the optimal dopants for new materials with improved properties, these fundamental insights into defect chemistry, defect-defect interactions, and oxygen ion diffusion dynamics and mechanisms can be used to accelerate the design of ceria defect systems.

\section{Conflicts of interest}

There are no conflicts of interest to declare

\section{Acknowledgements}

The authors acknowledge funding by The Danish Council for Independent Research Technology and Production Sciences for the DFF-Research Project 2, grant no. 48293 (Giant-E) and 6111-00145B (NICE); the European Union's Horizon 2020 research and innovation programme under Grant Agreement No. 801267 (BioWings); and VILLUM FONDEN, grant no. 00022862 (Iride).

\section{References}

1 T. Montini, M. Melchionna, M. Monai, and P. Fornasiero, Chem. Rev. 2016, 116, 5987-6041.

2 F. Teocoli, D. W. Ni, S. Sanna, K. Thyden, and V. Esposito, J. Mater. Chem. A. 2015, 3, 17135-17143.

3 N. Pryds and V. Esposito, J. Electroceram. 2017, 38, 1-23.

4 F. Teocoli, D. Ni, S. Sanna, K. Thyden, F. Fonseca, and V. Esposito, Scr. Mater. 2014, 75, 82-85.

5 R. Korobko, A. Patlolla, A. Kossoy, E. Wachtel, A. Frenkel, I. Lubomirsky, Giant electrostriction in Gd-doped ceria. Adv. Mater. 2012, 24, 5857-5861.

6 V. Esposito, D. Ni, Z. He, W. Zhang, A. Prasad, J. Glasscock, C. Chatzichristodoulou, S. Ramousse, A. Kaiser, Acta Mater. 2013 61, 6290-6300.

7 E. Balĺee, A. Ringuedé, M. Cassir, M. Putkonen, L. Niinisẗo, Chem. Mater. 2009, 21, 4614-4619.

8 M. Burbano, S. Norberg, S. Hull, S. Eriksson, D. Marrocchelli, P. Madden, and G. Watson, Chem. Mater. 2012, 24, 222-229.

9 J. Koettgen, S. Grieshammer, P. Hein, B. O. H. Grope, M. Nakayama, and M. Martin, Phys. Chem. Chem. Phys. 2018, 20, 14291-14321.

10 R. Schmitt, A. Nenning, O. Kraynis, R. Korobko, A. I. Frenkel, I. Lubomirsky, S. M. Haile, and J. L. M. Rupp, Chem. Soc. Rev. 2020,
49, 554-592.

View Article Online

11 S. Santucci, H. Zhang, S. Sanna, N. Pryds, DNIEsposittø,DARIP NAatek. 2019, 7, 071104.

12 A. Kabir, S. Santucci, N. V. Nong, M. Varenik, I. Lubomirsky, R. Nigon, P. Muralt, V. Esposito, Acta Mater. 2019, 174, 53-60.

13 D. Schweke, Y. Mordehovitz, M. Halabi, L. Shelly, S. Hayun, Adv. Mater. 2018, 30, 1-8.

14 T. Zhang, J. Ma, L. Kong, S. Chan, J. Kilner, Solid State Ionics. 2004, 170, 209-217.

15 D. Pérez-Coll, D. Marrero-López, P. Núñez, S. Piñol, J. R. Frade, Electrochim. Acta. 2006, 51, 6463-6469.

16 S. Omar, E. D. Wachsman, J. C. Nino, Solid State lonics. 2006, 177, 3199-3203.

17 W. Zajac, J. Molenda, Solid State lonics. 2008, 179, 154-158.

18 D. A. Andersson, S. I. Simak, N. V. Skorodumova, I. A. Abrikosov, B. Johansson, Proc. Natl. Acad. Sci. 2006, 103, 3518-3521.

19 M. C. Pearce, V. Thangadurai, Asia-Pac. J. Chem. Eng. 2009, 4, 3344.

20 H. Xu, H. Yan, Z. Chen, Solid State Sci. 2008, 10, 1179-1184.

21 D. E. P. Vanpoucke, P. Bultinck, S. Cottenier, V. V. Speybroeck, I. V. Driessche, J. Mater. Chem. A. 2014, 2, 13723-13737.

22 A. B. Kehoe, D. O. Scanlon, and G. W. Watson, Chem. Mater. 2011, 23, 4464-4468.

23 D. E. P. Vanpoucke, S. Cottenier, V. V. Speybroeck, I. V. Driessche, P. Bultinck, J. Am. Ceram. Soc. 2014, 97, 258-266.

24 F. A. Kröger, H. J. Vink, Solid State Phys.-Adv. Res. Appl. 1956, 3, 307-435.

25 M. Figaj, K. D. Becker, Solid State lonics. 2001, 141-142, 507-512.

26 K. Ackland, J. M. D. Coey, Phys. Rep. 2018, 746, 1-39.

27 S. P. Waldow, H. Wardenga, S. Beschnitt, A. Klein, R. A. De Souza, J. Phys. Chem. C. 2019, 123, 6340-6350.

28 D. S. Aidhy, Y. Zhang, W. J. Weber, J. Mater. Chem. A. 2014, 2, 1704-1709.

29 C. S. Wright, R. I. Walton, D. Thompsett, J. Fisher, S. E. Ashbrook, Adv. Mater. 2007, 19, 4500-4504.

30 H. Yamamura, S. Takeda, K. Kakinuma, J. Ceram. Soc. Japan. 2007, 474, 471-474.

31 A. M. D'Angelo, N. A. Webster, A. L. Chaffee, Inorg. Chem. 2016, 55, 12595-12602.

32 G. Dutta, U. V. Waghmare, T. Baidya, M. S. Hegde, K. R. Priolkar, and P. R. Sarode, Chem. Mater. 2006, 18, 3249-3256.

33 H. Jonsson, G. Mills, K. W. Jacobsen, Proc. Int. Sch. Phys. 1997, 387-403.

34 B. G. Dick, A. W. Overhauser, Phys. Rev. 1958, 112, 90-103.

35 N. F. Mott, M. J. Littleton, Trans. Faraday Soc. 1938, 34, 485-499.

36 J. D. Gale, J. Chem. Soc., Faraday Trans., 1997, 93, 629-637.

37 S. Plimpton, J. Comp. Phys., 1995, 117, 1-19.

38 a) W. G. Hoover, Phys. Rev. A, 1985, 31, 1695-1697; b) S. Nosé, J. Chem. Phys. 1984, 81, 511-519.

39 H. Zhang, A. H. H. Ramadan, R. A. De Souza, J. Mater. Chem. A. 2018, 6, 9116-9123.

40 P. Giannozzi, et al., J. Phys. Condens. Matter. 2009, 21, 395502.

41 G. Prandini, A. Marrazzo, I. E. Castelli, N. Mounet, N. Marzari, npj Comput. Mater. 2018, 4, 1-15.

42 C. W. M. Castleton, J. Kullgren, K. Hermansson, J. Chem. Phys. 2007, 127, 244704.

43 R. D. Shannon, Acta Crystallogr. B, 1969, B25, 925-946, also see http://abulafia.mt.ic.ac.uk/shannon/ptable.php.

44 N. Kim, J. F. Stebbins, Chem. Mater. 1997, 19, 5742-5747.

45 S. Sen, T. Edwards, S. K. Kim, S. Kim, Chem. Mater. 2014, 26, 19181924.

46 B. M. Reddy, A. Khan, P. Lakshmanan, M. Aouine, S. Loridant, and 
J.-C. Volta, J. Phys. Chem. B. 2005, 109, 3355-3363.

47 V. Esposito, D. W. Ni, D. Marani, F. Teocoli, K. T. Thyden, D. Z. D.

Florio, F. C. Fonseca, J. Mater. Chem. A. 2016, 4, 16871-16878.

48 H. Yahiro, K. Eguchi, H. Arai, Solid State lonics. 1986, 21, 37-47.

49 a) A. Kabir, J. R. Bowen, M. Varenik, I. Lubomirsky, V. Esposito, Materilia. 2020, 12, 100728; b) A. Kabir, J. K. Han, B. Merle, V. Esposito, Mater. Lett. 2020, 266, 127490; d) A. Kabir, H. Zhang, S. C.-Jørgensen, S. Santucci, S. Molin, V. Esposito, Script. Mater. 2020, 187, 183-187.

50 S. Grieshammer, B. O. H. Grope, J. Koettgen, M. Martin, Phys. Chem. Chem. Phys. 2014, 16, 9974-9986.

51 J. Koettgen, P. C. Schmidt, T. Bučko, M. Martin, Phys. Rev. B. 2018, 97, 1-11. 
Table of content

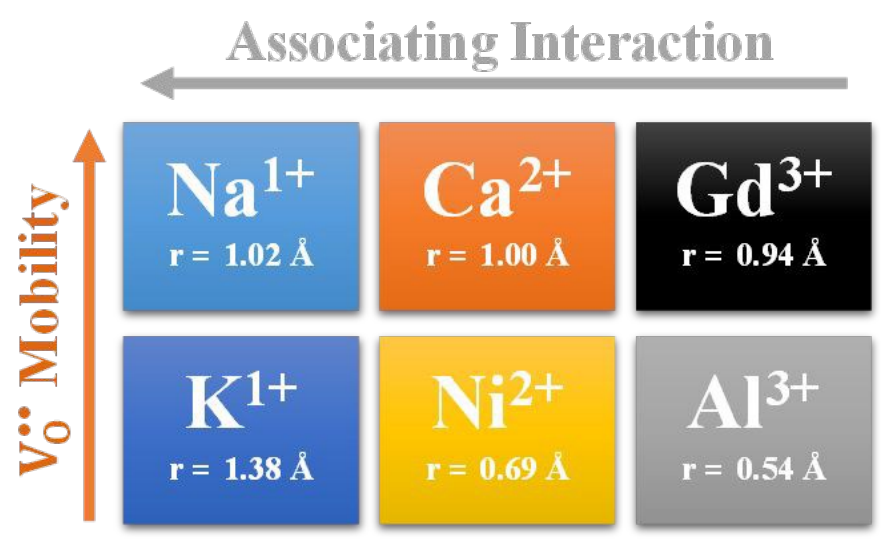

Atomic-scale simulations identify the substitutional chemistry of cerium oxide beyond the trivalent, rare-earth cations. 